\title{
Desempenho e características de carcaça de bovinos Nelore em confinamento alimentados com bagaço de cana-de-açúcar e diferentes fontes energéticas
}

\author{
Jane Maria Bertocco Ezequiel ${ }^{1}$, Rosemary Lais Galati ${ }^{2}$, Ana Rosália Mendes ${ }^{2}$, Cristian Faturi² \\ 1 Departamento de Zootecnia na FCAV/Unesp. \\ 2 Doutor em Zootecnia pela FCAV/Unesp.
}

RESUMO - Avaliaram-se o ganho de peso e as características da carcaça de bovinos Nelore alimentados com bagaço de cana-de-açúcar (in natura ou hidrolisado) como volumoso e concentrado contendo farelo de gérmen de milho, casca do grão de soja ou polpa de citrus em substituição parcial (50\%) ao milho. Quarenta bovinos Nelore (peso médio inicial de $340 \mathrm{~kg}$ e idade inicial de 32 meses) foram alimentados com quatro dietas fornecidas na proporção volumoso:concentrado 39:61. As fontes substitutivas do milho não afetaram o peso final $(470,8 ; 478,6 ; 476,4$ e 475,3 $\mathrm{kg})$ e o ganho médio diário (1,1; 1,1; 1,1 e $1,2 \mathrm{~kg} /$ animal/dia). Não houve efeito sobre o rendimento de carcaça $(55,3 ; 55,3 ; 54,0$ e 54,8\%), a área deLongissimus $\left(24,2 ; 23,0 ; 25,0\right.$ e $23,2 \mathrm{~cm}^{2} / 100 \mathrm{~kg}$ de carcaça) e a espessura de gordura $(4,4 ; 5,6 ; 4,7$ e 4,4 mm). O menor custo por arroba foi observado no tratamento com polpa de citrus (R\$44,20), seguido do farelo de gérmen de milho (R\$48,80) e da casca de soja ( $R \$ 50,80)$, porém, quando utilizado somente o milho, o custo da arroba foi de $\mathrm{R} \$ 51,80$. O milho moído pode ser parcialmente substituído pelo farelo de gérmen de milho, pela casca de soja ou pela polpa de citrus em dietas para bovinos em confinamento alimentados com bagaço de cana-de-açúcar (in natura ou hidrolisado) como volumoso, pois a substituição não alterou o ganho de peso e as características de carcaça.

Palavras-chave: casca de soja, conversão alimentar, farelo de gérmen de milho, ganho de peso, polpa decitrus, rendimento de carcaça

\section{Performance and carcass characteristics of feedlot Nellore fed diets containing sugarcane bagasse and different energy sources}

\begin{abstract}
The objective of this trial was to evaluate weight gain and carcass traits of feedlot Nellore fed diets containing sugarcane bagasse and one of the following concentrate sources: corn germ meal, soybean hulls or citrus pulp that partially (50\% DM) replaced ground corn in the diet. The four experimental diets were formulated to yield a forage:concentrate ratio of 39:61. Forty Nellore animals averaging $340 \mathrm{~kg}$ of body weight and 32 months of age at the beginning of the trial were used. No significant differences on final weight $(470.8,478.6,476.4$, and $475.3 \mathrm{~kg}$ ), weight gain $(1.1,1.1,1.1$, and $1.2 \mathrm{~kg}$.animal ${ }^{-1}$. day ${ }^{-1}$ ), carcass yield $(55.3,55.3,54.0$ and 54.8\%), Longissimus area $(24.2,23.0,25.0$, and $23.2 \mathrm{~cm}^{2} .100 \mathrm{~kg}^{-1}$ of carcass), and backfat thickness $(4.4,5.6,4.7$, and $4.4 \mathrm{~mm}$ ) were observed among the four concentrate sources. The lowest cost per arroba was observed when ground corn was partially replaced by citrus pulp ( $\mathrm{R} \$ 44.20$ ) followed by corn germ meal ( $\$$ \$ 48.80) and soybean hulls ( $\mathrm{R} \$ 50.80$ ); the diet containing only ground corn as the energy source had the greatest cost per arroba produced (R \$ 51.80). It can be concluded that ground corn can be partially replaced by corn germ meal, soybean hulls or citrus pulp in diets for feedlot Nellore also receiving hydrolyzed sugar cane bagasse with no detrimental effects in weight gain and carcass traits.
\end{abstract}

Key Words: carcass dressing, citrus pulp, corn germ meal, feed conversion, soybean hulls, weight gain

\section{Introdução}

A incorporação do confinamento nos sistemas de produção de bovinos de corte aumentou $69 \%$ nos últimos oito anos, passando para aproximadamente 2,5 milhões de cabeças em 2004. Apesar desse aumento, a engorda em confinamento correspondeu a apenas 5,3\% do total estimado para 2005
(Anualpec, 2005), gerando perspectivas para aumento de sua participação futura.

Esse perfil demonstra que a pecuária nacional está mais especializada, garantindo destaque do Brasil na produção mundial de carne, com volume de exportações que confere ao país a primeira posição mundial, com 1,8 milhões de toneladas (Anualpec, 2005). 
Entre os fatores que ainda desestimulam o confinamento, encontra-se a qualidade dos ingredientes e, conseqüentemente, da dieta oferecida, pois seu uso inadequado afeta de forma severa o desempenho animal, com reflexos sobre os índices produtivos. Além disso, o impacto econômico da alimentação representa aproximadamente $85 \%$ do custo da atividade produtiva, sendo o concentrado o principal limitante responsável nesse sistema (Leme et al., 2003).

$\mathrm{Na}$ tentativa de minimizar esses custos, os produtos alternativos provenientes das agroindústrias (resíduos e subprodutos) atingiram qualidade, transformando-se em co-produtos. Tornou-se, portanto, importante a avaliação de co-produtos da agroindústria com melhor valor comercial e que não prejudiquem o desempenho dos animais.

A partir da industrialização da cana-de-açúcar, obtém-se o bagaçoin natura, um subproduto muito difundido na alimentação de bovinos durante a década de 80 , principalmente na Região Sudeste, onde se concentram as indústrias sucroalcooleiras. Entre os subprodutos da canade-açúcar, o bagaço in natura representa o maior volume de produção e constitui um desafio na alimentação animal, tendo em vista seu baixo valor nutritivo (Ezequiel \& Andrade, 1988; Berndt et al., 2002). Esse é um fator limitante quanto ao uso desse bagaço, que é muito difundido na geração de energia elétrica. $\mathrm{O}$ uso de bagaço na alimentação animal constitui um desafio, porque esse subproduto é de baixo valor nutritivo e tem alto custo de produção.

Como alternativa, a hidrólise do bagaço com pressão e vapor torna-o mais digestível, mas pode diminuir o consumo (Virmond, 2001). Prado et al. (1995) utilizaram o bagaço de cana-de-açúcar hidrolisado e verificaram viabilidade em sua utilização em dietas para bovinos em confinamento. Contudo, seu uso requer a suplementação com concentrado em níveis variáveis conforme o potencial de produção dos animais (Henrique et al., 1999; Leme et al., 2003) como forma de minimizar os custos da alimentação. Nas regiões sucroalcooleiras, com o término da safra, os bagaços in natura e hidrolisado podem acumular nas usinas, o que desperta o interesse de produtores, pois sua aquisição se torna extremamente vantajosa frente à desvalorização. Com essa perspectiva, o custo da alimentação diminui tornando a atividade viável e rentável.

Entre os concentrados, o milho moído tem sido o ingrediente mais substituído, destacando-se como potenciais substitutos a polpa de citrus, a casca do grão de soja e o farelo de gérmen de milho, entre outros. Schalch et al. (2001), ao substituírem o milho por polpa de citrus, não encontraram diferenças no desempenho de bovinos e concluíram que o nível de substituição pode ser de até $100 \%$.
Henrique et al. (1998) observaram que, em dietas contendo baixas proporções de concentrado (20\%), o milho pode ser totalmente substituído por polpa de citrus. Entretanto, quando o concentrado constitui $80 \%$ da dieta, dependendo do nível de inclusão, a substituição total pode afetar o consumo. Galati et al. (2003) e Mendes et al. (2005) avaliaram a substituição parcial (de 56 e 70\%) do milho pela casca do grão de soja e pelo farelo de gérmen de milho em dietas para bovinos em confinamento e não observaram efeito sobre o desempenho ( 1,1 a $1,4 \mathrm{~kg} / \mathrm{dia})$ e as características de carcaça. Essas substituições corresponderam, em média, ao fornecimento de 1,0 a 1,8 kg/dia de casca do grão de soja ou do farelo de gérmen de milho com a perspectiva de economia de pelo menos $10 \%$ na aquisição de ingredientes.

Objetivou-se com este trabalho avaliar o ganho de peso e as características de carcaça de bovinos Nelore alimentados com dietas contendo bagaço de cana como volumoso e farelo de gérmen de milho, casca do grão de soja ou polpa de citrus em substituição parcial (50\%) ao milho moído.

\section{Material e Métodos}

O experimento foi realizado no período de junho a outubro de $2002 \mathrm{em}$ uma propriedade particular situada no município de Lins - SP.

Quarenta bovinos Nelore criados em pastagem (idade inicial de 32 meses e peso médio inicial de $340 \mathrm{~kg}$ ) foram pesados e distribuídos ao acaso em quatro tratamentos. Em virtude do tamanho e do número de baias da instalação onde o confinamento foi conduzido, os animais foram alojados em baias coletivas (cinco animais/baia), sendo duas por tratamento. O confinamento era totalmente coberto e dividido em baias pavimentadas de $30 \mathrm{~m}^{2}$.

No início do experimento, os animais foram tratados com Ivermectina para controle de endo e ectoparasitos. Para adaptação às dietas e uniformização do consumo, foi utilizado um período de 24 dias, desconsiderado nas avaliações de ganho de peso.

$\mathrm{Na}$ Tabela 1 encontram-se as composições bromatológicas dos ingredientes utilizados nas formulações. Os tratamentos foram compostos por dietas contendo $39 \%$ de volumoso (bagaço de cana-de-açúcar hidrolisado e in natura) e $61 \%$ de concentrado (\%MS), tendo como fontes nitrogenadas levedura de cana-de-açúcar, farelo de algodão e uréia. Como fonte energética, utilizaram-se milho moído (tratamento MI - controle), farelo de gérmen de milho (tratamento FGM), casca do grão de soja (tratamento CS) e polpa de citrus (tratamento PC) em substituição a 50\% do milho, compondo os tratamentos (Tabela 2). Todos os ingredientes dos concentrados foram moídos a $3 \mathrm{~mm}$. 
Tabela 1 - Composição bromatológica dos ingredientes utilizados nas formulações Table 1 - Chemical composition of the dietary ingredients

\begin{tabular}{|c|c|c|c|c|c|}
\hline \multirow[t]{4}{*}{$\begin{array}{l}\text { Ingrediente } \\
\text { Ingredient }\end{array}$} & \multicolumn{5}{|c|}{$\begin{array}{l}\text { Composição } \\
\text { Composition }\end{array}$} \\
\hline & \multirow{3}{*}{$\begin{array}{c}\mathrm{MS} \\
D M \\
\%\end{array}$} & \multirow{2}{*}{$\begin{array}{l}\text { MO } \\
\text { OM }\end{array}$} & $\begin{array}{c}\text { PB } \\
C P\end{array}$ & $\begin{array}{l}\text { FDN } \\
N D F\end{array}$ & $\begin{array}{l}\text { FDA } \\
A D F\end{array}$ \\
\hline & & & & \multirow{2}{*}{$\begin{array}{l}\% \mathrm{MS} \\
D M \%\end{array}$} & \\
\hline & & & & & \\
\hline Bagaço de cana-de-açúcar hidrolisado (Hydrolyzed sugar cane bagasse) & 48,0 & 98,0 & 1,8 & 59,0 & 53,9 \\
\hline Farelo de gérmen de milho (Corn germ meal) & 89,1 & 95,8 & 14,0 & 26,4 & 8,8 \\
\hline Casca do grão de soja (Soybean hulls) & 90,5 & 94,9 & 12,2 & 72,5 & 56,9 \\
\hline Polpa de citrus(Citrus pulp) & 89,9 & 94,7 & 8,5 & 25,0 & 24,0 \\
\hline Melaço de cana-de-açúcar (Sugar cane molasses) & 72,1 & - & 5,0 & - & - \\
\hline Levedura de cana-de-açúcar (Sugar cane yeast) & 93,5 & 92,5 & 30,1 & - & - \\
\hline Farelo de algodão (Cottonseed meal) & 89,0 & 92,7 & 40,8 & 32,0 & 17,0 \\
\hline
\end{tabular}

Tabela 2 - Composição percentual dos tratamentos experimentais (\%MS)

Table 2 - Ingredient composition of the experimental diets (\%DM)

\begin{tabular}{|c|c|c|c|c|}
\hline \multirow[t]{2}{*}{$\begin{array}{l}\text { Ingrediente } \\
\text { Ingredient }\end{array}$} & \multicolumn{4}{|c|}{$\begin{array}{c}\text { Tratamento } \\
\text { Diet }\end{array}$} \\
\hline & MI & $\begin{array}{c}\text { FGM } \\
C G M\end{array}$ & $\begin{array}{l}\mathrm{CS} \\
\mathrm{SH}\end{array}$ & $\begin{array}{l}\mathrm{PC} \\
C P\end{array}$ \\
\hline Bagaço de cana-de-açúcar hidrolisado (Hydrolyzed sugar cane bagasse) & 36,0 & 36,0 & 36,0 & 36,0 \\
\hline Bagaço de cana-de-açúcar in natura (In natura sugar cane bagasse) & 3,0 & 3,0 & 3,0 & 3,0 \\
\hline Milho moído (Ground corn) & 35,4 & 18,8 & 18,3 & 17,0 \\
\hline Farelo de gérmen de milho (Corn germ meal) & - & 18,8 & - & - \\
\hline Casca do grão de soja (Soybean hulls) & - & - & 18,3 & - \\
\hline Polpa de citrus(Citrus pulp) & - & - & - & 17,0 \\
\hline Melaço de cana-de-açúcar (Sugar cane molasses) & 5,0 & 5,0 & 5,0 & 5,0 \\
\hline Levedura de cana-de-açúcar (Sugar cane yeast) & 8,5 & 8,5 & 8,5 & 8,5 \\
\hline Farelo de algodão (Cottonseed meal) & 11,2 & 9,0 & 10,0 & 12,6 \\
\hline Uréia (Urea) & 0,9 & 0,9 & 0,9 & 0,9 \\
\hline
\end{tabular}

${ }^{1}$ MI: milho moído; FGM: farelo de gérmen de milho em substituição a 50\% do milho moído; CS: casca do grão de soja em substituição a $50 \%$ do milho moído; PC: polpa de citrus em substituição a $50 \%$ do milho moído.

${ }^{1}$ GC: treatment containing ground corn; CGM: treatment containing corn germ meal replacing $50 \%$ of ground corn; SH: treatment containing soybean seed hulls replacing $50 \%$ of ground corn; CP: treatment containing citrus pulp replacing $50 \%$ of ground corn.

As dietas foram calculadas para serem isoprotéicas (14\% de PB, em \% MS), segundo recomendações do AFRC (1993), de forma a proporcionar ganho de $1,0 \mathrm{~kg} /$ dia. Os animais receberam alimentação duas vezes ao dia, às $6 \mathrm{e} 17 \mathrm{~h}$, permitindo-se sobras (diariamente recolhidas e pesadas). A cada dieta adicionou-se $0,025 \%$ de monensina sódica. O suplemento mineral $(\mathrm{Ca}=100,0 \mathrm{~g}$; $\mathrm{P}=50,4 \mathrm{~g} ; \mathrm{Na}=251,9 \mathrm{~g} ; \mathrm{Cl}=408,5 \mathrm{~g} ; \mathrm{Zn}=5.040,0 \mathrm{mg}$; $\mathrm{Cu}=2.228,7 \mathrm{mg} ; \mathrm{Co}=218,2 \mathrm{mg} ; \mathrm{I}=118,0 \mathrm{mg} ; \mathrm{S}=19.091,0 \mathrm{mg})$ foi fornecido separadamente na quantidade correspondente a $60 \mathrm{~g} / \mathrm{animal} / \mathrm{dia}$.

Nos ingredientes foram determinados os teores de MS, cinzas e PB ( $\mathrm{N}$ x 6,25) pelo método de micro-kjeldahl (AOAC 1995), e os de FDN e FDA (Van Soest, 1967). A digestão foi submetida a controle de temperatura e pressão em autoclave por 60 minutos a 0,5 atm e $111^{\circ} \mathrm{C}$ (adaptado de Pell \& Schofield, 1992).

Foram realizadas pesagens a cada 28 dias para acompanhamento individualizado do ganho de peso e, aos 94 dias de experimento, foram abatidos três animais de cada tratamento (em um total de 12 bovinos) que haviam atingido peso mínimo de $450 \mathrm{~kg}$. Foram retirados obrigatoriamente os animais presentes nas duas baias de cada tratamento, mantendo-se os demais até 133 dias em confinamento. Os animais foram pesados após jejum alimentar de 14 horas somente no início do período experimental e na última pesagem que antecedeu o abate.

O abate foi realizado em frigorífico comercial para avaliação individual do peso de carcaça quente e do rendimento de carcaça por meio da pesagem das carcaças 
ao final da linha de abate. As meias-carcaças direitas, resfriadas por 24 horas, foram utilizadas para as avaliações das características qualitativas e quantitativas. Foi medido o comprimento de carcaça, correspondente à distância entre as bordas cranial do púbis (em seu ponto médio) e cranial da primeira costela (Johnson, 1996), além do comprimento de perna e de braço, do perímetro de braço e da espessura de coxão (Müller, 1987). Em cada meia-carcaça, o músculo Longissimus foi seccionado entre a 12 a e $13 \underline{a}$ costelas e o contorno foi traçado com papel vegetal, efetuando-se a medida da área (AL) por meio do equipamento “Digital Image Analysis System", Version 1.12 ${ }^{\circledR}$. Em torno do músculoLongissimusfoi medida a espessura de gordura subcutânea (EGS) a partir da média de três pontos.

O delineamento utilizado foi o inteiramente casualizado, com quatro tratamentos e dez repetições, e os dados referentes ao peso inicial, ao peso final, ao ganho médio diário, ao rendimento de carcaça, à área de Longissimus, à espessura de gordura subcutânea, ao comprimento de carcaça, ao comprimento de perna, à espessura de coxão, ao comprimento e ao perímetro de braço foram submetidos à análise de variância pelo procedimento GLM do software Statistical Analysis Systems ${ }^{\circledR}$ (SAS, 1995). As diferenças entre as médias foram avaliadas pelo teste Tukey a $5 \%$ de probabilidade.

Para a análise dos custos, considerou-se o valor do boi magro como de R \$ 635,00 no estado de São Paulo. O valor de mercado pago ao produtor pela arroba de animais rastreados foi de $\mathrm{R} \$ 63,00$. Considerou-se, para a análise econômica os pesos iniciais e finais, os ganhos diários e os rendimentos de carcaça quente obtidos em cada tratamento.

\section{Resultados e Discussão}

As médias de peso inicial, peso final, ganho médio diário, rendimento e características de carcaça encontram-se na Tabela 3. Não foi observado efeito da substituição do milho pelo farelo de gérmen de milho, pela casca do grão de soja ou pela polpa de citrus, embora neste último tratamento o ganho tenha sido ligeiramente superior. As variações encontradas para peso inicial foram decorrentes da diferença na resposta animal durante o período de adaptação.

Os dados de desempenho apresentados neste trabalho corroboram outros resultados observados na literatura nos quais a inclusão da polpa decitrus, do farelo de gérmen de milho ou da casca do grão de soja em substituição ao milho não afetou o desempenho animal (Galati et al., 2003;
Henrique et al., 2004; Mendes et al., 2005). Sugere-se como possível explicação a existência de sub-estimativa do valor nutritivo desses ingredientes, pois foi pequena a correspondência entre o aproveitamento de alguns desses ingredientes e os desempenhos proporcionados pelas dietas nas quais foram incluídos.

Rocha Jr. et al. (2003) determinaram o valor energético de diversos ingredientes, entre eles o fubá de milho, o gérmen de milho e a casca de soja, e observaram 93,75; 85,30 e 68,95\% de NDT, respectivamente. No NRC (2001) são apresentados valores de 79,8; 88,7; 83,1 e 67,3\% de NDT para a polpa de citrus, o milho moído, o gérmen de milho e a casca do grão de soja, respectivamente. Essas diferenças proporcionariam desempenhos diferentes, contudo, não é isso que ocorre quando co-produtos são utilizados, o que provoca sério questionamento quanto aos componentes nutritivos analisados para a obtenção do NDT. Supõe-se que outros componentes, provavelmente de origem fibrosa, como a fibra solúvel (Faturi, 2005; Ezequiel \& Galati, 2005), façam parte desses ingredientes e que, no ambiente ruminal, favoreçam o crescimento microbiano. Assim, a fração solúvel da fibra e que tem valor nutricional não faria parte do NDT, explicando sua subestimativa. Parece ser agravante o fato de que as metodologias convencionais de análise não são capazes de determinar essas frações diferenciadas e que estão presentes nos co-produtos da agroindústria.

O consumo de MS é um dos fatores primários na conversão do alimento em produto animal, de modo que o consumo de MS digestível é mais afetado pelo consumo de MS que pela própria digestibilidade (Waldo, 1986). A partir do controle diário de sobras em cada baia, foi estimado o consumo de MS observando-se que a introdução da casca do grão de soja não foi limitante quando comparada aos demais tratamentos $(7,8$ vs 7,5; 7,4 e 7,7 kg/dia para o tratamento CS, MI, FGM e PC, respectivamente). Em contrapartida, o tratamento CS tendeu a apresentar pior conversão alimentar (7,1 vs 6,9; 6,7 e 6,4 kg MS ingerida/kg ganho, na mesma ordem citada), contudo, esses dados podem não ser conclusivos quanto à viabilidade de utilização desse ou dos demais ingredientes. É preciso analisar as características de desempenho associadas à avaliação econômica para obtenção de um tratamento de destaque aplicável frente à competição econômica.

Prado et al. (2000), avaliando níveis de substituição do milho pela polpa de citrus, não encontraram diferenças $(\mathrm{P}<0,05)$ para o ganho de peso $(1,35 \mathrm{a} 1,39 \mathrm{~kg} / \mathrm{animal} / \mathrm{dia}) \mathrm{e}$ as características de carcaça em bovinos machos inteiros $\mathrm{F}_{1}$ (Nelore x Angus) alimentados com dietas com 51\% de silagem de milho. Gomes (1998) substituiu integralmente o 
Tabela 3 - Variáveis de desempenho, consumo, conversão alimentar e características de carcaça dos animais e respectivos coeficientes de variação (CV)

Table 3 - Performance, feed intake, feed conversion, carcass characteristics, and correspondent coefficients of variation (CV)

\begin{tabular}{|c|c|c|c|c|c|}
\hline \multirow[t]{3}{*}{$\begin{array}{l}\text { Variável } \\
\text { Item }\end{array}$} & \multicolumn{4}{|c|}{$\begin{array}{c}\text { Fonte de energia }{ }^{1} \\
\text { Concentrate }^{1}\end{array}$} & \multirow[t]{3}{*}{$\mathrm{CV}(\%)$} \\
\hline & MI & FGM & $\mathrm{CS}$ & $\mathrm{PC}$ & \\
\hline & $G C$ & $C G M$ & SH & $C P$ & \\
\hline Peso inicial, kg (Initial weight, kg) & 339,8 & 350,2 & 345,7 & 334,5 & 7,2 \\
\hline Peso final, $\mathrm{kg}$ (Final weight, $\mathrm{kg}$ ) & 470,8 & 478,6 & 476,4 & 475,3 & 7,0 \\
\hline Ganho médio diário, kg/dia (Weight gain, kg.day-1) & 1,1 & 1,1 & 1,1 & 1,2 & 26,8 \\
\hline Rendimento de carcaça (\%) (Carcass yield, \%) & 55,3 & 55,3 & 54,0 & 54,8 & 3,1 \\
\hline Área de Longissimus, $\mathrm{cm}^{2}$ (Longissimus area, $\mathrm{cm}^{2}$ ) & 62,7 & 60,2 & 64,2 & 60,5 & 10,3 \\
\hline Área de Longissimus $\left(\mathrm{cm}^{2} / 100 \mathrm{~kg}\right.$ de carcaça) (Longissimus area, $\mathrm{cm}^{2} .100 \mathrm{~kg}_{\text {of }}$ carcass $^{-1}$ ) & 24,2 & 23,0 & 25,0 & 23,2 & 10,7 \\
\hline Espessura de gordura subcutânea, mm (Backfat thickness, $\mathrm{mm}$ ) & 4,4 & 5,6 & 4,7 & 4,4 & 40,4 \\
\hline Comprimento de carcaça, $\mathrm{cm}$ (Carcass length, $\mathrm{cm})$ & 128,2 & 127,0 & 128,7 & 128,2 & 2,4 \\
\hline Comprimento de perna, cm (Hind leg length, $\mathrm{cm}$ ) & 83,8 & 82,4 & 83,4 & 83,9 & 2,7 \\
\hline Espessura de coxão, $\mathrm{cm}$ (Beef round thickness, $\mathrm{cm}$ ) & 29,4 & 29,3 & 27,8 & 29,3 & 8,1 \\
\hline Comprimento de braço, $\mathrm{cm}$ (Fore leg length, $\mathrm{cm})$ & 46,0 & 44,6 & 45,4 & 46,0 & 4,5 \\
\hline Perímetro de braço, $\mathrm{cm}$ (Fore leg perimeter, $\mathrm{cm}$ ) & 37,0 & 36,4 & 37,2 & 36,9 & 3,7 \\
\hline
\end{tabular}

Médias seguidas pela mesma letra, na linha, não diferem pelo teste Tukey $(P<0,05)$.

Means followed by the same letters in the row did not differ by Tukey test $(P<0.05)$.

${ }^{1} \mathrm{MI}$ : milho moído; FGM: farelo de gérmen de milho em substituição (50\%) ao milho moído; CS: casca do grão de soja em substituição (50\%) ao milho moído; PC: polpa de citrus em substituição $(50 \%)$ ao milho moído.

${ }^{1}$ GC: treatment containing ground corn; CGM: treatment containing corn germ meal replacing $50 \%$ of ground corn; SH: treatment containing soybean seed hulls replacing $50 \%$ of ground corn; $C P$ : treatment containing citrus pulp replacing $50 \%$ of ground corn.

milho pela casca de soja em dietas para garrotes $F_{1}$ (Nelore $x$ Angus) em confinamento alimentados com bagaço de cana hidrolisado e não notou nenhum efeito sobre o ganho (média 1,35 kg/dia)

Galati et al. (2003), ao avaliarem o desempenho de novilhos Nelore em confinamento alimentados com $60 \%$ de silagem de milho e concentrado contendo farelo de gérmen de milho ou casca do grão de soja como fontes energéticas substitutas parciais do milho (70\%), não observaram diferença significativa para o ganho médio diário, embora a dieta com farelo de gérmen de milho tenha proporcionado ganho $7,7 \%$ mais elevado em relação às demais (1,3 vs $1,4 \mathrm{~kg} / \mathrm{dia})$.

A média observada para rendimento de carcaça (54,9\%) encontra-sena amplitude de variação considerada adequada (53 a 59\%) para novilhos Nelore (Jorge et al., 1999) e pode estar relacionada ao grau de acabamento das carcaças (4,8 mm de espessura de gordura subcutânea - EGS), que esteve entre os 3 a $5 \mathrm{~mm}$ exigidos para obtenção de carcaças com padrão adequado e evitar perdas por desidratação, além de escurecimento da carne durante o resfriamento (Muller, 1987). Para o produtor que trabalha com venda a rendimento, o bom atendimento desse parâmetro evita o recorte da gordura excessiva e a conseqüente redução no peso da carcaça.

Observou-se tendência de maior EGS no tratamento FGM, que apresentou valor $24,4 \%$ numericamente mais elevado que a média dos demais tratamentos, contudo, o elevado coeficiente de variação $(40,4 \%)$ impossibilitou a confirmação estatística. Essa característica, quando bem manipulada, pode ser interessante para o consumidor e, neste caso, seria importante avaliar as propriedades organolépticas proporcionadas por esse tratamento. A utilização do farelo de gérmen de milho parece ser ainda mais vantajosa quando utilizados volumosos de baixa qualidade. Nesse caso, a possibilidade de aumento na participação do volumoso sem que a qualidade da carcaça seja diminuída pode ser interessante desde que essa manipulação não prejudique a rentabilidade.

Mendes et al. (2005) observaram aumento de $17 \%$ no valor de EGS com a substituição parcial (57\%) do milho pelo farelo de gérmen de milho. Galati et al. (2003) também observaram que a EGS de novilhos Nelore alimentados com dieta contendo farelo de gérmen de milho $(5,5 \mathrm{~mm})$ foi numericamente mais elevada que a obtida com a substituição parcial do milho (70\%) pela casca de soja $(4,9 \mathrm{~mm})$. Ressalta-se que, em ambos os trabalhos, utilizou-se silagem de milho como volumoso, de qualidade superior aos bagaços de cana-deaçúcar. Parece não haver dúvidas quanto à relação entre o farelo de gérmen de milho e a maior EGS. Não se sabe, no entanto, se essa tendência é decorrente de possíveis diferenças entre as relações de ácidos graxos voláteis no rúmen, dos níveis de glicose sangüínea ou de outro metabolismo, uma vez que, do ponto de vista nutricional, pode-se considerar que o farelo de gérmen de milho proporciona resultados semelhantes aos de milho moído (Galati, 2004).

A média de área de Longissimus $\left(61,9 \mathrm{~cm}^{2}\right)$ obtida foi próxima à observada por Mendes et al. (2005), de 63,6 cm², em novilhos 3/4 Simental 1/4 Nelore alimentados com 55\% 
de silagem de milho, milho, casca de soja e farelo de gérmen de milho como fontes energéticas. Galati et al. (2003), avaliando dietas com $60 \%$ de silagem de milho e concentrados contendo farelo de gérmen de milho e casca de soja como fontes energéticas, substitutos parciais $(70 \%)$ ao milho, observaram que a área de Longissimus foi, em média, de 59,2 $\mathrm{cm}^{2}$ para novilhos Nelore.

Os valores encontrados nas medidas de desenvolvimento de carcaça não foram influenciados $(\mathrm{P}<0,05)$ pelas diferentes fontes energéticas. Essas características são indicativas do porte dos animais e estão relacionadas à raça e idade dos animais. Assim, as medidas que se relacionam diretamente à hipertrofia muscular, como a espessura de coxão e o perímetro de braço, são indicativas do rendimento muscular na carcaça. Neste trabalho, as médias de comprimento de carcaça, comprimento de perna, espessura de coxão, comprimento de braço e perímetro de braço evidenciaram o crescimento similar dos animais, proporcionado pela homogeneidade dos lotes e pelos ganhos de peso. Dados semelhantes foram citados por Galati et al. (2003), que obtiveram, para bovinos da raça Nelore, valores de 126,$0 ; 25,7$ e $36,1 \mathrm{~cm}$ para comprimento de carcaça, espessura de coxão e perímetro de braço, respectivamente.

Com relação ao bagaço de cana-de-açúcar hidrolisado, salienta-se que a fragmentação da estrutura física da parede celular (Burgi, 1985) pode afetar o consumo de MS (Virmond, 2001). Contudo, alguns autores relataram o potencial de uso desse volumoso e destacaram que pode haver efeito associativo do volumoso aos demais ingredientes da dieta (Boin, 1987; Prado et al., 1995; Magalhães et al., 1999). Assim, os ingredientes e seus níveis utilizados, quando combinados adequadamente de acordo com sua cinética digestiva, podem proporcionar bom desempenho. Os ingredientes, apesar de suas características bromatológicas, podem não ser eficientemente aproveitados pelos animais, mas, quando utilizados nas proporções e em associações adequadas, possibilitam a exploração de suas características intrínsecas.

$\mathrm{Na}$ Tabela 4 encontra-se a análise econômica para engorda dos bovinos da raça Nelore em confinamento para cada tratamento. As quatro dietas proporcionaram ganhos econômicos atrativos, demonstrando que, mesmo com o aumento no preço de aquisição dos insumos no início do período de confinamento, é possível obter lucro.

O lucro e o sucesso de um confinamento dependem de diversos fatores que iniciam com a escolha do peso inicial e do preço pago pelo boi magro. O planejamento estratégico do confinamento, considerando a melhor época de aquisição dos insumos e o período de compra dos animais, são de extrema importância, pois, como apresentado na Tabela 4 , somente o lucro com a transferência do valor do boi magro para o boi gordo pode representar até $40 \%$ do lucro total dentro do sistema. Recomenda-se que todos os fatores sejam equacionados e controlados periodicamente para que o resultado final seja satisfatório, de modo que o lucro proporcionado pelo ganho de peso seja maximizado por meio do aumento na eficiência de utilização dos alimentos ou pelo menor preço de aquisição.

Considerando as quatro fontes energéticas utilizadas, verificou-se que, enquanto a tonelada do milho foi comercializada a $\mathrm{R} \$ 320,00$, os custos de aquisição do farelo de gérmen de milho ( $\mathrm{R} \$ 280,00)$, da casca do grão de soja $(\mathrm{R} \$ 235,00)$ e da polpa de $\operatorname{citrus}(\mathrm{R} \$ 180,00)$ foram 12,$5 ; 26,6$ e 44,0\% menores que o do milho, respectivamente. O resultado foi o menor custo da alimentação e por arroba produzida quando o milho foi parcialmente (50\%) substituído. O menor custo por arroba foi obtido com a dieta contendo polpa de citrus $(\mathrm{R} \$ 44,20)$, seguida dos tratamentos com farelo de gérmen de milho ( $R \$ 48,80)$ e casca de soja $(R \$ 50,80)$, porém, quando utilizado somente o milho, o custo da arroba foi de $\mathrm{R} \$ 51,80$, o que esteve diretamente relacionado ao preço de aquisição de cada ingrediente.

O total da receita obtida dependeu do valor da arroba pago na venda dos animais, determinado pelo maior ou menor desempenho. Uma parte da receita foi relativa à venda do peso do animal adquirido magro e vendido posteriormente a preço de boi gordo e a outra, da venda das arrobas de carcaça produzidas durante o confinamento, considerando o peso de abate e o rendimento de carcaça proporcionado pelos tratamentos. As pequenas diferenças observadas no peso ao abate dos animais e no rendimento resultaram em maior receita no tratamento contendo farelo de gérmen de milho, seguido por aqueles com polpa de citrus e casca de soja, sendo menor quando utilizado o milho moído.

Os custos totais com alimentação resultaram em maiores lucros por animal confinado nos tratamentos contendo farelo de gérmen de milho $(\mathrm{R} \$ 275,80)$ e polpa de citrus ( $\mathrm{R} \$ 261,80)$, que corresponderam a 15,8 e 10,0\% mais lucro em relação ao milho moído, respectivamente. Embora o tratamento com polpa de citrus tenha proporcionado o melhor ganho de peso, não foi apontado, nesta análise econômica, como o melhor tratamento, pois fatores como rendimento de carcaça e consumo foram determinantes nessa avaliação.

Os dados ressaltam a importância do planejamento estratégico do confinamento e do adequado balanceamento das dietas para exploração do efeito associativo entre ingredientes e a utilização de produtos com preço mais favorável e que não comprometam o desempenho animal. 
Tabela 4 - Análise econômica para alimentação na engorda de bovinos Nelore em cada tratamento (valores expressos em R\$) Table 4 - Economic analysis for feeding of feedlot Nellore in each treatment (values expressed in $R \$$ )

Fonte de energia

Concentrate

\begin{tabular}{llll}
\hline MI & FGM & CS & PC \\
$G C$ & $C G M$ & $S H$ & $C P$ \\
\hline
\end{tabular}

Custos (Costs)

Custo do animal (Animal cost)

Custo alimentação (Feed cost)

$635,00 \quad 635,00$

$220,30 \quad 200,80$

635,00

635,00

Total despesas (Total expense)

855,30

835,80

209,12

198,70

Custo da arroba produzida (Cost per arroba produced)

51,80

48,80

844,10

832,10

44,20

Receitas (Income)

Valorização do peso inicial ${ }^{1}$ (Initial weight valorization)

713,58

1093,50

Total da receita (Total income)

Lucros (Profit)

Ganho em peso (Weight gain)

Diferença no preço do boi magro para o boi gordo

Difference in cattle price before and after finishing

Total do lucro (Total profit)

1 Valor do peso inicial dos animais no momento da venda, considerando o preço de $R \$ 63,00$ para a arroba.
1 Value of initial weight at sale considering the value of $R \$ 63.00$ per arroba.

\section{Conclusões}

O farelo de gérmen de milho, a casca do grão de soja e a polpa de citrus podem substituir parte do milho moído utilizado na formulação de dietas para bovinos em confinamento.

A associação das fontes energéticas substitutivas do milho com os bagaços de cana-de-açúcar como volumosos não afetou o ganho de peso e as características de carcaça.

A escolha do ingrediente para substituição do milho moído não deve ser restrita apenas ao seu valor econômico, mas sim mediante análise detalhada do sistema intensivo.

\section{Agradecimento}

À Caramuru Alimentos Ltda. Itumbiara-GO, pelo fornecimento da casca de soja e do farelo de gérmen de milho.

Aos proprietários da Fazenda São Joãozinho, Lins-SP, e ao Zootecnista Cristiano Reinaldo Prado, pelas condições oferecidas para a condução desse trabalho.

Ao Frigorífico Bertin, Lins - SP, por viabilizar o estudo das características de carcaça em suas instalações.

\section{Literatura Citada}

AGRICULTURAL AND FOOD RESEARCH COUNCIL - AFRC. Energy and protein requirements of ruminants. Wallingford: CAB International, 1993. 159p.

ANUALPEC. Anuário da pecuária brasileira. São Paulo: FNP Consultoria e Comércio, FNP Agro Informativos, 2005. 340p.
ASSOCIATION OF OFFICIAL ANALYTICAL CHEMISTRY AOAC. Official methods of analysis. 16.ed. Arlington: Patricia Cunnif, 1995. 1025p.

BERNDT, A.; HENRIQUE, W.; LANNA, D.P.D et al. Milho úmido, bagaço de cana e silagem de milho em dietas de alto teor de concentrado, composição corporal e taxas de deposição dos tecidos. Revista Brasileira de Zootecnia, v.31, n.5, p.21052112, 2002.

BOIN, C. Cana-de-açúcar na alimentação de ruminantes. In: CONGRESSO PAULISTA DE AGRONOMIA, 6., 1987, Piracicaba. Anais... Piracicaba: Escola Superior de Agricultura "Luiz de Queiroz", 1987. p.55-57.

BURGI, R. Produção do bagaço de cana-de-açúcar (Saccharum sp L.) auto-hidrolisado e avaliação para ruminantes. Piracicaba: Escola Superior de Agricultura "Luiz de Queiroz", 1985. 61p. Dissertação (Mestrado em Ciência Animal e Pastagens) - Escola Superior de Agricultura "Luiz de Queiroz", 1985.

EZEQUIEL, J.M.B.; ANDRADE, P. Avaliação de rações contendo bagaço de cana-de-açúcar e palha de arroz. Ingestão e digestibilidade. Revista da Sociedade Brasileira de Zootecnia, v.17, n.5, p.466-455, 1988.

EZEQUIEL, J.M.B.; GALATI, R.L. Qualidade da matéria prima e novos testes laboratoriais como instrumento de maximização da dieta balanceada. In: REUNIÃO ANUAL DA SOCIEDADE BRASILEIRA DE ZOOTECNIA, 42., 2005, Goiânia. Anais... Goiânia: Sociedade Brasileira de Zootecnia, 2005. p.298-321.

FATURI, C. Fontes de carboidratos solúveis e níveis de fibra em detergente neutro em dietas para terminação de novilhos em confinamento. Jaboticabal: Universidade Estadual Paulista, 2005. 73p. Tese (Doutorado em Zootecnia) - Universidade Estadual Paulista, 2005.

GALATI, R.L.; EZEQUIEL, J.M.B.; SILVA, O.G.C. et al. Desempenho e características da carcaça de novilhos Nelore alimentados com dietas contendo casca de soja ou farelo de gérmen de milho substituindo parcialmente o milho. In REUNIÃO ANUAL DA SOCIEDADE BRASILEIRA DE ZOOTECNIA, 40., 2003, Santa Maria. Anais... Santa Maria: Sociedade Brasileira de Zootecnia, 2003. (CD-ROM)

GALATI, R.L. Co-produtos do milho, soja e girassol em dietas para bovinos de corte. Jaboticabal: Universidade Estadual 
Paulista, 2004. 168p. Tese (Doutorado em Zootecnia) Universidade Estadual Paulista, 2004.

GOMES, I.P.O. Substituição do milho pela casca de soja em dietas com diferentes proporções de volumoso: concentrado para bovinos em confinamento. Jaboticabal: Universidade Estadual Paulista, 1998. 84p. Tese (Doutorado em Zootecnia) - Universidade Estadual Paulista, 1998.

HENRIQUE, W.; LEME, P.R.; LANNA, D.P.D. et al. Substituição de amido por pectina em dietas com diferentes níveis de concentrado. 1. Desempenho animal e características da carcaça. Revista Brasileira de Zootecnia, v.27, n.6, p.1206-1211, 1998.

HENRIQUE, W.; LEME, P.R.; LANNA, D.P.D. et al. Avaliação do milho úmido com bagaço de cana ou silagem de milho na engorda de bovinos. 1. Desempenho animal e características da carcaça. In: REUNIÃO ANUAL DA SOCIEDADE BRASILEIRA DE ZOOTECNIA, 36., 1999, Porto Alegre.Anais... Porto Alegre: Sociedade Brasileira de Zootecnia, 1999 (CD-ROM).

HENRIQUE, W.; SAMPAIO, A.A.M.; LEME, P.R. et al. Desempenho e características da carcaça de tourinhos Santa Gertrudes confinados, recebendo dietas com alto concentrado e níveis crescentes de polpa cítrica peletizada. Revista Brasileira de Zootecnia, v.33, n.2, p.463-470, 2004.

JOHNSON, E.R. Beef carcass caracteristics that may be of value in selecting for genetic merit. Australian Veterinary Journal, v.73, n.6, p.233-240, 1996.

JORGE, A.M.; FONTES, C.A.A.; PAULINO, M.F. et al. Desempenho produtivo de quatro raças zebuínas, abatidos em três estádios de maturidade. 2. Características da carcaça. Revista Brasileira de Zootecnia, v.28, n.2, p.381-387, 1999.

LEME, P.R.; SILVA, S.L.; PEREIRA, A.S.C. et al. Utilização do bagaço de cana-de-açúcar e, dietas com elevada proporção de concentrados para novilhos Nelore em confinamento. Revista Brasileira de Zootecnia, v.32, n.6, p.1786-1791, 2003.

MAGALHÃES, L.R.G.; VASQUEZ, H.M.; COELHO DA SILVA, J.F. Bagaço hidrolisado e ponta de cana-de-açúcar (Sacharum officinarum), associados a duas fontes protéicas, na engorda de bovinos em confinamento. Revista Brasileira de Zootecnia, v.28, n.4, p.822-830, 1999.

MENDES, A.R.; EZEQUIEL, J.M.B.; GALATI, R.L. et al. Desempenho, parâmetros plasmáticos e características de carcaça de novilhos alimentados com farelo de girassol e diferentes fontes energéticas, em confinamento. Revista Brasileira de Zootecnia, v.34, n.2, 624-634, 2005.

MÜLLER, L. Normas para avaliação de carcaças e concurso de carcaças de novilhos. Santa Maria: Universidade Federal de Santa Maria, 1987. 31p.
NATIONAL RESEARCH COUNCIL - NRC. Nutrient requirements of dairy cattle. 7.ed.rev. Washington, D.C.: National Academic Press, 2001. 381p.

PELL, A.N.; SCHOFIELD, P. Computerized monitoring of gas production to measure forage digestion in vitro. Journal of Dairy Science, v.76, n.4, 1063-1073, 1992.

PRADO, I.N.; BRANCO, A.F.; ZEOULA, L.M. et al. Performance and characteristics of feedlot nelore steers, feed 15 or $30 \%$ of whole cottonseed, auto- hidrolized bagasse of sugar cane and sugar cane or elephant grass. Arquivos de Biologia e Tecnologia, v.38, n.2, p.353-365, 1995.

PRADO, I.N.; PINHEIRO, A.D.; ALCALDE, C.R. et al. Níveis de substituição do milho pela polpa de citrus peletizada sobre o desempenho e características de carcaça de bovinos mestiços confinados. Revista Brasileira de Zootecnia, v.29, n.6, p.2135-2141, 2000.

ROCHA JR., V.R.; VALADARES FILHO, S.C.; BORGES, A.M. et al. Determinação do valor energética de alimentos para ruminantes pelo sistema de equações. Revista Brasileira de Zootecnia, v.32, n.2, p.473-479, 2003.

SCHALCH, F.J.; SCHALCH, E.; ZANETTI, M.A. et al. Substituição do milho em grão moído pela polpa cítrica na desmama precoce de bezerros leiteiros. Revista Brasileira de Zootecnia, v.30, n.1, p.280-285, 2001.

STATISTICAL ANALYSIS SYSTEMS - SAS. Language guide. v.6. 3.ed. Cary: 1995. 530p.

Van SOEST, P.J. Development of a comprehensive system of feed analysis and its applications to forage. Journal of Animal Science, v.26, n.1, p.119-128, 1967.

VIRMOND, M. Avaliação do bagaço de cana tratado com diferentes agentes químicos através de estudos de cinética ruminal e ensaios de digestibilidade. Pirassununga: Universidade de São Paulo, 2001. 82p. Dissertação (Mestrado em Zootecnia) - Universidade de São Paulo, 2001.

WALDO, D.R. Effect of forage quality on intake and forageconcentrate interactions. Journal of Dairy Science, v.69, n.4, p.617-631, 1986. 